\title{
Expressions of equity: imbalances in the patient-clinician interaction
}

\author{
SHOBHA MOCHERLA ${ }^{1,2}$, USHA RAMAN $^{3}$, BRIEN HOLDEN ${ }^{4}$
}

Audio-Visual Producer, Central Audio-Visual Unit (CAVU), L V Prasad Eye Institute, Banjara Hills, Hyderabad INDIA 2Doctoral Candidate, Brien Holden Vision Institute, University of New South Wales, Sydney AUSTRALIA ${ }^{3}$ Associate Professor, Sarojini Naidu School of Arts and Communication, University of Hyderabad, Hyderabad, Andhra Pradesh INDIA ${ }^{4}$ Chief Executive Officer, Brien Holden Vision Institute, University of New South Wales, Sydney AUSTRALIA Author for correspondence: Shobha Mocherla e-mail: mshoba@lvpei.org

\section{Abstract}

This paper reports patient perceptions of inequities in the doctorpatient interaction. A mixed method study was conducted in a tertiary eye care centre in southern India to gain an insight into patient understanding and satisfaction from clinician communication. Non-participant observations enabled us to map the sequence of communication opportunities in the clinical interaction, and in-depth interviews were used to identify patient perceptions of the content and clarity of clinician communication in a clinic for patients of glaucoma, a chronic eye disease. A 60item instrument was administered to 550 participants in the quantitative phase to explore associations between patient expectations, experience and ratings of clinician communication and satisfaction with it.

The qualitative results helped map the clinical interaction, highlighting the consequences of poor clinician communication. The quantitative phase showed that patients expected explanations about the disease, the opportunity to ask questions, receiving supportive signals, and being treated as equals.

Most patients stated their information source on disease was their doctor, leading us to conclude that clinicians must utilise communication opportunities optimally to ensure every patient has an equal chance to correctly understand their disease and role in treatment. By consciously improving their communication and using it strategically, clinicians can help ensure effective treatment outcomes.

\section{Introduction}

Clinician-patient communication is an aspect studied mostly in western clinical settings with findings pointing to insurance status, site of care, race and ethnicity as causes of variation in care (1). There is little research in India on the impact of clinician communication both on patient understanding of disease management and on patient satisfaction with the clinician's communication. This paper reports the partial results of a study of patient perceptions of clinician communication in a tertiary care glaucoma clinic in India that looked at the possible sources of inequity in the clinical interaction. The findings address the gap in our comprehension of what the patient takes away from the clinical interaction, a matter which is crucial in relation to the care of chronic disease. Given that the patient's informed understanding influences his or her adherence to the doctor's advice (2), do doctors communicate variably to match the patient's profile or level of understanding? The patient's correct understanding of disease is particularly important in the Indian context as here the doctor's advice is taken to be unquestionable, with the doctor being looked at as a Godfigure.

\section{Background}

Structural and contextual factors grouped under the head "social determinants of health" (3-4) are acknowledged constraints that often compromise active patient participation in the medical interaction. Patient age, gender, education, disease severity, language, and socioeconomic status can be overwhelming extraneous factors that can affect the clinical interaction outcomes $(5,6)$.

Equity in healthcare access and service delivery has been an important consideration in the assessment of social inclusion, but equity has been understood largely in terms of financial and geographical access to services. In this paper, we argue that an important element of equity is social access to and provision of care-how friendly and receptive are medical systems to patients from different socioeconomic and cultural backgrounds? To what extent do care providers foster a culture of equity at the site of delivery? How do patients perceive and react to power differentials in the context of healthcare delivery? How does this affect the perceptions of quality of care? These are some of the questions that drive the present study.

Ensuring equitable access to eye care services requires advocacy at the community, district and state levels (7). Thus, patient empowerment, wherein the patient correctly understands and learns to take equal responsibility for his or her health, may be supported or constrained by the social context (8). Communication is a tool for patient empowerment, and, acknowledging this, the WHO urges the use of information and mass communication campaigns to address the needs of people to control their own health (9).

The clinician-patient interaction is an important part of the healthcare cycle, established as a significant moderator of patient experience and satisfaction, both of which are factors in ensuring patient participation in and adherence to a treatment plan (10). Studies have found that physician communicative behaviours such as empathy and information-giving are moderated by patient socio-demographics (11). Inequalities in health are a source of social inequity, and economic inequities 
form a large part of this public health problem (12). The onus of generating or ensuring patient participation and achieving doctor-patient communion rests on building a firm partnership through the clinician's psychosocial talk and sharing control with the patient (13). Other studies have indicated that education improves doctor-patient communication and moderates patients' receptivity to instructions and consequent willingness to implement the treatment plan (14).

Health inequalities in the clinic exist the world over and may be caused by language discordance $(15,16)$, the patient's level of education (17), age (18) and social gradient of health (19), and the physician's cultural competence and patientcenteredness (20).

Mechanisms that leverage inter-departmental or intergovernmental action on universal insurance and equitable resource allocation give us a chance to address health inequities (21). Strategies to remove cultural disparities include simplification of the health system's complexity to benefit especially those patients who have no proficiency in English (or the dominant language of the establishment) and have low health literacy (22). The patient-provider relationship is built on effective clinician communication and the patient benefits by receiving the doctor's affective personal attention during routine medical care through the creation of "teachable moments" in the interaction (23). When patients perceive clinician communication to be collaborative, they also tend to better adhere to medications, as was seen in an empirical study of patients with uncontrolled hypertension (24).

In countries such as India, where wide disparities exist across socio-economic, cultural and linguistic categories, it is important to remember that "non-modern" patients especially stand to lose from the interaction when doctors do not have the social skills to adequately educate the patient (25).

Adequacy of patient understanding is a hallmark of good clinician communication, indicating how well the clinician's message has been received whatever the patient's background (socioeconomic status, cultural and linguistic lineage). This study of patient perceptions sought to explore the potential inequities that can occur due to inadequate utilisation of communication opportunities during the clinical interaction. The qualitative part of the research aimed to map the clinician-patient interaction and analyse the patient's perspective. The quantitative phase of the research aimed to explore relationships between some of the variables of interest emerging from the qualitative findings, across the patient spectrum.

\section{Method}

The study was conducted over two and a half years during 2007-2009 in the glaucoma clinic of a tertiary care eye centre in Hyderabad, a southern Indian city. The centre receives patients from all socioeconomic and cultural categories, with subsidised or free care available to those who cannot pay. The centre also receives referrals from individual and institutional practices across the country.
Glaucoma is a chronic eye disease that requires frequent return visits to the clinic to evaluate the extent of disease progression from the current eye pressure and status of the optic nerve. The first two phases of the study involved 51 non-participant observations of clinician-patient interactions and 28 in-depth, face-to-face interviews with patients of the glaucoma clinic. The ethnographic work was situated within the paradigm of Symbolic Interactionism with the data analysed by the constant comparison method to inductively interpret emergent themes (26). The qualitative interviews $(\mathrm{N}=28)$ were conducted in English, mostly with paying patients. This was followed by a researcher-administered survey $(\mathrm{N}=550)$ conducted in English, Telugu and Hindi with roughly equal numbers of paying patients and non-paying patients.

\section{Results}

The study outcomes of the qualitative phase indicated that inequities exist in clinician communicative behaviour and that greater visible empathy on the part of the clinician during the consultation could improve the doctor-patient relationship. The survey outcomes indicated that patient socio-economic status and level of education influenced patients' expectations of the interaction as well as their rating of the interaction experience, and their satisfaction with clinician communication.

\section{Understanding patients' perspectives}

Emergent themes from the in-depth patient interviews included the following areas of disparity in eye care service delivery: inequity by patient's age, gender, geographic background, payment category, education, language spoken, and presence of an attendant/companion. These are elaborated here under the three sub-sections: patient parity, communication equity and physician deification.

\section{A. Seeing through the parity prism}

We often assume variations in communication expectations across socioeconomic categories and thus tailor our own communications to these expectations. The same appears to be true of medical professionals as well, as was indicated in our research. One rural patient observed that they should be clearly told of diagnostic tests available elsewhere even when the doctor could not offer these. Only a few paying patients have medical insurance and many find it difficult to pay out of pocket for ongoing treatment. Patients found the cost of care was prohibitive if there was no medical reimbursement. Several patients had no expectations about receiving compassionate care from the doctor perhaps because they perceived themselves as belonging to a lower status. Patients perceived that doctors accorded preferential treatment to paying patients, in terms of giving more time, attention or priority, sometimes calling certain patients to the clinic ahead of others in apparently 'out of turn' consultations. Differences in the length of conversation, the display of respect and eye contact, and their own understanding of the severity of the disease appeared to contribute to such perceptions. As such, patients of lower socio-economic status (non-paying patients) are less 
likely to ask questions to clarify doubts, and also have lower expectations of the doctor's responsiveness in the interaction.

$\operatorname{Dr}$ A gives special treatment to those who are wealthy and their relatives, the rest of us are general category general people; that is my feeling, since he would not attend to us and make us wait instead while he would attend to others in that time, ... everyone is commercial - money talks.

Patient 23 of 28, male, retired principal of a government school, age 71 years

Here neither did I ask nor did they explain

Patient 24 of 28, female home-maker, age 65 years

My expectations of doctors are that they should speak well, clear all my doubts and be affectionate [kind, compassionate] and friendly. Only then can we speak to them of our problems. If we fear the doctor then we cannot possibly talk to them about any of our problems. If [it's a] friendly doctor, then we can speak freely. That's what we expect of a doctor - to be friendly, mild mannered.

Patient 2 of 28, female teacher, age 51 years

How come he (the doctor) does not smile and speak to me at the end by way of reassurance? (drily): NO [no diagnosis was told to me]! [The doctor told me] Only to put eyedrops!

Patient 27 of 28, male agriculturist/farmer, age 54 years

Physicians play an important role in equalising the power relations between themselves and patients, by using a variety of communicative tools. For instance, phatic communication, or social talk that does not have any direct connection with the medical aspects of care, can be used for this purpose. We found that such communication appears to be the preserve of long-time patient-doctor associations. Patients appreciated the doctor's expressions of humour, small talk and ability to engage them in conversation.

They are good, and the way they greet you here with laughing face and not getting irritated, even [if] I don't answer properly they will [patiently] ask 2-3 times, it's nice.

Female patient, healthcare professional, urban, paying patient, educated, age 64 years

Dr $\mathrm{Y}$ has learnt a little bit of Telugu and says "Maataaji" [mother] [laughs] - he did not know Telugu in the beginning, now he has learnt a bit, when he says "Maataaji" I say "what Maataaji when you make me wait so long, so many hours", then he says "Oh Maataaji is angry with us, let us attend to her fast and send her on her way." So then it cools me down! [smiles]

Female patient, housewife, urban, paying patient, educated, age 65 years

The patient's level of education might be a concern for doctors running busy schedules as they may make assumptions about uneducated patients requiring longer or more detailed explanations and instructions, and the pressure of time prevents them from repeating an instruction or asking a check question.

More than the treatment we have to give, [the gentleness of their] talk, that impresses the patients, in Telugu they say "Oka manchi maata" ("One good word works wonders") so to say a good word and encourage them actually you don't require so much of treatment. More than for the educated, we have to tell the uneducated, we have to explain that is very important.

Female patient, healthcare professional, urban, paying patient, educated, age 64 years

Access also pertains to patient location, with cities certainly offering more facilities for all kinds of patients. Patients residing in urban areas have the advantage of access to healthcare facilities as well as to cross-referrals within the clinical setting that people of rural areas may not readily have. Diagnosis, follow-up visits, and cross referrals are more readily available to those living in cities and towns compared to those in the rural areas.

I think I am fortunate that I live in a big city like Hyderabad and access to good treatment is available to me and (if) more such opportunities are made available so that rural people also get the same treatment it would be nice.

Female patient, urban, paying patient, highly educated, age 63 years

\section{B. Expressions of equity regarding the doctor's communication skills}

Rural patients were satisfied when directly spoken to and when doubts were clarified. They did not in general expect doctors to do this routinely. There was a general notion that familiarity with clinicians was essential to have one's doubts clarified. Patients sought reassurance from the doctor's explanations and deplored prolonged waiting times. In our observations, clinicians often spoke to the patient's attendant rather than to the patient, at times even excluding the patient from the conversation as if they were not present.

I don't know if it is because that doctor (elsewhere) was from a village or because he was a small-time doctor but he never tested me with so many instruments! Here they speak well, it is very nice, they all spoke well and I am very happy as if my eyesight is already restored!

Male patient, rural patient, paying patient, educated, age 60 years

We are not asking to stay on and speak but to speak in the time that he is there with us!

Male patient, rural, paying patient, educated, age 54 years

They asked me to sit in the examination chair, spoke to me nicely, patiently, otherwise in some hospitals doctors are brash and hurried and speak abruptly, here in this 
hospital they speak with love and affection for the patient. Half the battle with the disease is thereby won in the hospital precincts with the clinician here speaking compassionately to the patient.

Male patient, paying patient, educated, age 63 years

It is a thrill to watch Dr Y speak to the patient personally, by using the name of the patient and touching the shoulder with compassion and giving a warm handshake.

Male attendant, male patient, rural, educated, paying patient, age 68 years

\section{Deification of doctors and its consequences}

Doctors were repeatedly referred to as 'god' or 'god-like', making apparent the dependence of the patient on the doctor to manage their eye health. The decision-making was left to the doctor, who had a disproportionate share of the power in the clinical interaction, and often chose to exercise the power by not engaging in conversation or by not responding to patient's "non-medical" comments.

Doctors are equal to God, what they know they help patients to repair their health. When a patient in the house needs a doctor we look for a doctor with a good name.

\section{Patient 17 of 28 , male, toddy tapper, age 44 years}

The doctor is like a family friend, cooperates, is like a God, like a gift of God this $\operatorname{Dr} Y$ is like God. Always positive, calm, not like he is a doctor and we are a patient, he does not instil fear in us.

Patient 16 of 28, male, bank clerk, age 55 years. His daughter too has the same eye condition.

Patients felt unequal to the doctor, indicating a clear perception of hierarchy-deference, with the social and cultural norms entering the clinical space too. But one of the patients did ask: is clinician communicativeness the same for all?

Polite - definitely! [laughs] Hope they are polite to everybody like that? Are they? See, some people they are very polite to the English educated. Villagers they treat very roughly. I don't know about these doctors.

Patient 22 of 28, female, retired principal of a government degree college, age 63 years

\section{Results, part two: exploring relationships}

Based on the main themes that emerged from the observations and interviews, a 60-item instrument was designed and administered to 550 patients in the quantitative phase to explore associations between patients' expectations, experience and satisfaction with clinicians' communication. It was hypothesised that patients' perceptions would vary by demographics such as socioeconomic status, gender, age and education. We hypothesised that the patient's socioeconomic status would significantly influence the interaction in terms of expectations, experience of interaction, rating of communicative behaviour, and outcomes related to understanding and satisfaction.

\section{Patient pool}

The patient pool in this quantitative survey included 281 paying and 250 non-paying patients, 350 male patients and 181 female patients, 305 patients who had no education or had some schooling or completed high school (up to the $10^{\text {th }}$ grade) and 226 patients who were educated beyond the $10^{\text {th }}$ grade, and 141 patients under 45 years of age and 390 patients over 45 years of age.

Patients' expectations, experience and satisfaction were identified as constructs of interest and items related to these constructs were included in the survey instrument (Tables 1 to 3 below). SPSS (SPSS ver. 16.0 for Windows; SPSS, Chicago, IL) was used to analyse the data.

The construct Patient Expectations comprised the following items: I expect the doctor to (i) explain the eye condition in a way that the patient can understand, (ii) give the patient an opportunity to ask questions, (iii) be supportive and acknowledge the patient's fears about the eye condition, and (iv) treat the patient as an equal.

The construct Patient Recall of Experience, labelled "Communication Index", was built with the items: The doctor (i) recognised me, (ii) greeted me pleasantly, (iii) addressed me by name, (iv) looked at me when speaking, and (v) spoke to me in my language.

The construct Patient Ratings of Experience was itemised using: This doctor (i) made me feel my eye condition can be correctly treated, (ii) was caring, (iii) encouraged me to ask questions, (iv) cleared the doubts I had about my eye condition, (v) gave me instructions about the prescribed medications, and (vi) spoke to my attendant when explaining the treatment to me.

The construct Patient Satisfaction with Communication included the items: How satisfied are you that your doctor (i) helped in reducing your worries about this eye condition, (ii) explained the treatment to you in a way that made you feel that you better understood your eye condition, and (iii) told you about the importance of continuing this treatment for glaucoma? The survey also included items that captured how much the patients knew and understood about the eye condition, glaucoma, and where their information came from. Patients' knowledge showed significance for the patient's socioeconomic status and level of education (Tables 1,2 and 3). 
Table 1: Patients' level of knowledge about glaucoma

\begin{tabular}{|l|l|l|}
\hline Level of knowledge & $\begin{array}{l}\text { Frequency } \\
\mathbf{N = 5 3 1}\end{array}$ & $\begin{array}{l}\text { Percentage } \\
\mathbf{( 1 0 0 \% )}\end{array}$ \\
\hline $\begin{array}{l}\text { Knowledge level zero or six incorrect } \\
\text { responses }\end{array}$ & 20 & 3.8 \\
\hline $\begin{array}{l}\text { Knowledge level one or five incorrect } \\
\text { responses }\end{array}$ & 94 & 17.7 \\
\hline $\begin{array}{l}\text { Knowledge level two or four incorrect } \\
\text { responses }\end{array}$ & 70 & 13.2 \\
\hline $\begin{array}{l}\text { Knowledge level three or three } \\
\text { incorrect responses }\end{array}$ & 61 & 11.5 \\
\hline $\begin{array}{l}\text { Knowledge level four or two incorrect } \\
\text { responses }\end{array}$ & 79 & 14.9 \\
\hline $\begin{array}{l}\text { Knowledge level five or one incorrect } \\
\text { response }\end{array}$ & 131 & 24.7 \\
\hline $\begin{array}{l}\text { Knowledge level six or all six correct } \\
\text { responses }\end{array}$ & 76 & 14.3 \\
\hline
\end{tabular}

Table 2: Patients' knowledge and patient socioeconomic status

\begin{tabular}{|c|c|c|c|c|}
\hline Category & $\begin{array}{l}\text { Low } \\
\text { knowledge } \\
\text { (n=184, } \\
\underline{34.7 \%)}\end{array}$ & $\begin{array}{l}\frac{\text { High }}{\text { knowledge }} \\
\text { (n=347, } \\
\underline{65.3 \%)}\end{array}$ & $\begin{array}{l}\frac{\text { Total }}{(\mathrm{N}=531} \\
\mathbf{1 0 0 \% )}\end{array}$ & $\begin{array}{l}\text { Chi- } \\
\text { square } \\
\text { (Asymp } \\
\text { Sig. 2- } \\
\text { sided) }\end{array}$ \\
\hline $\begin{array}{l}\text { Paying } \\
\text { patient }\end{array}$ & $\begin{array}{l}43 \\
(23.4 \%)\end{array}$ & 238 (68.6\%) & 281 (52.9\%) & \multirow{2}{*}{.0001} \\
\hline $\begin{array}{l}\text { Non-paying } \\
\text { patient }\end{array}$ & 141 (76.6\%) & 109 (31.4\%) & 250 (47.1\%) & \\
\hline
\end{tabular}

Table 3: Patients' knowledge and level of education

\begin{tabular}{|c|c|c|c|c|}
\hline Category & $\begin{array}{l}\text { Low } \\
\text { knowledge } \\
\text { (n=184, } \\
34.7 \%)\end{array}$ & $\begin{array}{l}\text { High } \\
\text { knowledge } \\
(n=347, \\
65.3 \%)\end{array}$ & $\begin{array}{l}\begin{array}{l}\text { Total } \\
(\mathrm{N}=531,\end{array} \\
100 \%)\end{array}$ & $\begin{array}{l}\text { Chi- } \\
\text { square } \\
\text { (Asymp } \\
\text { Sig. 2- } \\
\text { sided) }\end{array}$ \\
\hline $\begin{array}{l}\text { Non-literate } \\
\text { or studied up } \\
\text { to } 10^{\text {th }} \text { grade }\end{array}$ & 154 (83.7\%) & 151 (43.5\%) & $\begin{array}{l}305 \\
(57.4 \%)\end{array}$ & \multirow{2}{*}{.0001} \\
\hline $\begin{array}{l}\text { Studied } \\
\text { beyond } 10^{\text {th }} \\
\text { grade }\end{array}$ & $30(16.3 \%)$ & 196 (56.5\%) & $\begin{array}{l}226 \\
(42.6 \%)\end{array}$ & \\
\hline
\end{tabular}

Student's independent samples t-test showed that there is a significant difference in the average level of knowledge about glaucoma between the two socioeconomic groups of paying and non-paying patients $(t=12.38 \mathrm{df}=500.526 \mathrm{p}=.0001)$ and between those who were referred to this clinic by another doctor and those who were self-referred $(t=2.142 \mathrm{df}=482.099$ $p=.033$ ) and between those patients who were non-literate or had studied up to tenth grade and those who had studied beyond tenth grade $(t=12.15 \mathrm{df}=523.940 \mathrm{p}=.0001)$. However, gender, location and age did not seem to influence the level of knowledge.

\section{Different backgrounds, expectations and experiences}

Chi-square tests showed significant differences in the responses across the items measuring these constructs (expectations, experience and satisfaction) among patients from different socioeconomic groups.

Patients from different socioeconomic strata had different levels of expectations and experience of interaction, as well as different levels of ratings of and satisfaction with communication in the clinic. Table 4 summarises the data of these four constructs by socioeconomic status.

Table 4: Patients' expectations, experience, ratings of experience, and satisfaction with clinicians' communication and the patient's socioeconomic status

\begin{tabular}{|l|l|l|l|l|}
\hline \multirow{2}{*}{$\begin{array}{l}\text { Construct } \\
\mathbf{N}=\mathbf{5 3 1}\end{array}$} & Category & $\begin{array}{l}\text { Paying } \\
\text { patients } \\
\mathbf{n = 2 8 1} \\
\mathbf{( 5 2 . 9 \% )}\end{array}$ & $\begin{array}{l}\frac{\text { Non-paying }}{\text { patients }} \\
\mathbf{n = 2 5 0}\end{array}$ & $\begin{array}{l}\mathbf{( 4 7 . 1 \% )} \\
\text { Total } \\
\mathbf{N}=\mathbf{5 3 1}\end{array}$ \\
\hline $\begin{array}{l}\text { Patients' } \\
\text { expectations }\end{array}$ & Low & $\begin{array}{l}50 \\
(34.0)\end{array}$ & $97(66.0)$ & $147(27.7)$ \\
\cline { 2 - 5 } & High & $231(60.2)$ & $153(39.8)$ & $\begin{array}{l}384 \\
(72.3)\end{array}$ \\
\hline $\begin{array}{l}\text { Patients' recall } \\
\text { of experience } \\
\text { (Commun-ication } \\
\text { index) }\end{array}$ & Low recall & $26(29.5)$ & $62(70.5)$ & $88(16.6)$ \\
\cline { 2 - 5 } & High recall & $255(57.6)$ & $188(42.4)$ & $\begin{array}{l}443 \\
(83.4)\end{array}$ \\
\hline \multirow{2}{*}{$\begin{array}{l}\text { Patients' ratings } \\
\text { of experience }\end{array}$} & Low rating & $42(28.0)$ & $108(72.0)$ & $\begin{array}{l}150 \\
(28.2)\end{array}$ \\
\cline { 2 - 5 } & High rating & $239(62.7)$ & $142(37.3)$ & $\begin{array}{l}381 \\
(71.8)\end{array}$ \\
\hline \multirow{2}{*}{$\begin{array}{l}\text { Patients' } \\
\text { satisfaction }\end{array}$} & Low & $54(33.5)$ & $107(66.5)$ & $\begin{array}{l}161 \\
(30.3)\end{array}$ \\
\cline { 2 - 5 } & High & $227(61.4)$ & $143(38.6)$ & $\begin{array}{l}370 \\
(69.7)\end{array}$ \\
\hline
\end{tabular}

Crosstabs for all four constructs showed significance ( $p$ value $<.0001)$ for differences in responses to all constructs by the patient's socioeconomic status.

\section{Patients' knowledge source}

The doctor topped the list for almost all patients, when asked about the most important source of information about their eye condition (Table 5).

\section{Table 5: Sources of information on eye condition}

\begin{tabular}{|l|l|}
\hline Source of information & $\begin{array}{l}\mathbf{N u m b e r} \text { of patients } \\
\mathbf{( N = 5 3 1 )}\end{array}$ \\
\hline Eye doctor & $522(98.3 \%)$ \\
\hline Neighbour & $16(3.0 \%)$ \\
\hline Other patients & $42(7.9 \%)$ \\
\hline Family member & $52(9.8 \%)$ \\
\hline $\begin{array}{l}\text { Mass media (radio, television, } \\
\text { newspapers) }\end{array}$ & $138(26.0 \%)$ \\
\hline Internet & $30(5.6 \%)$ \\
\hline Other sources, if any & $50(9.4 \%)$ \\
\hline
\end{tabular}

\section{Analysis and discussion}

Our results indicate that a variety of socioeconomic and cultural factors play a role in the nature and course of the 
patient-physician interaction. This could influence the level of understanding of medical information and instructions, apart from increasing compliance and "buy in" from the patient. If physicians are aware of these nuances in expectations and attitudes, they can compensate for them by using communication strategically in ways that make patients feel comfortable and more empowered to seek and act on advice and information.

In chronic diseases, self-care is crucial to the long-term management of the disease, and the doctor's supportive stance helps the patient clearly understand the steps of treatment and voluntarily comply with the treatment plan given by the doctor. Correct understanding of the disease and the treatment rationale is thus a prerequisite for adherence and compliance. While this study was not designed to explore the relationship between communication and compliance, it may be surmised from the results and from previously cited reports that understanding and satisfaction can encourage compliance. The doctor's easily understandable talk and friendly manner can help the patient learn to avoid the limiting consequences of chronic disease. By giving instructions sequentially, cogently and coherently, the doctor fulfils his/her relational responsibility to the patient.

The interviews with patients also revealed that many patients take advice from their physician very seriously, and consider the doctor an authority figure, implying therefore that information provided by their physician will be acted upon. It is thus imperative that health education must begin, continue and be reinforced by clinicians in the clinic. Clinicians should consciously focus on educating their patients about the steps of treatment, the consequences of the disease and the likely outcomes of treatment. In addition, they may need to recognise and address the biases and assumptions that prevent them from interacting with all patients in a manner that engages them. The use of write-ups enriched with visuals might enable low literacy patients to better understand their disease condition and the steps that will help them to overcome or mitigate their problem.

Clinicians in India work under the pressure of time and are also called on to equitably meet patient diversity. In this context, as elsewhere, mechanical doctoring can be counterproductive to achieving health outcomes. Patients often do not feel comfortable asking questions to clarify doubts because they feel they are intruding on the doctor's time. Clinicians' therapeutic behaviour, say, friendly eye contact or addressing the patient by name, could make them appear approachable and ease the patient into a trusting relationship with their doctor, one that will empower them to understand why they are being told to do something, what they have to do, and how they can effortlessly do it.

The clinician's compassionate attention could capture the imagination of patients and inspire them to role-play the adherent-patient's role, supporting every patient's wish to overcome behaviours that limit recovery or contribute to the progression of a disease. The frequent and purposeful use of clinician Communication Bonuses through communicative acts can improve the doctor-patient relationship, regardless of whether the patient is educated or not, of the paying category or not. Similarly, variations in patients' expectations of, experience of, ratings of and satisfaction with clinician communication due to the patient's socioeconomic status can be negated by the clinician's Communication Bonuses including the convincing enactment of warmth, spontaneity, attentive concern for and genuine interest in the patient as a person. Clinicians' use of Communication Disincentives such as absence of eye contact, lack of a smile or friendly approach, use of technical language, or use of a language that is alien to the patient, looking and speaking only to the attendant as if the patient is not present and so on could impede the doctor-patient relationship. As the doctor is the main source of information for most patients, clinicians' deliberate communicative acts can enhance the quality of the relationship.

It is not for the first time that it has been suggested that socioemotional communication skills have to be taught during medical school just as are routine pre-clinical skills. Evidence is yet to be established that can associate communication competence training with improved equity in clinician services (27). In the West, this has come to be the established practice with core syllabi including student orientation in psychosocial verbal talk and cross-cultural skills. However, in India, communication skills for use with populations with diverse backgrounds, expectations, and health experiences have not been formally taught in undergraduate and postgraduate medical education curricula. Medical education in the country needs to be revamped to incorporate communication skills training as a core syllabus topic for engendering compassion and tolerance in those who will be career clinicians. Reflexive practitioners will be better prepared to meet the demands of patients from diverse cultural populations.

Developing a healthy perspective of patients' conditioning, background and social status, or, better still, learning to be blind to patients' default socioeconomic and cultural loci, can help clinicians to provide truly empathic psychosocial care (28). Psychosocial determinants of health are acknowledged as being key to the success of the interaction. In a culture that looks to physicians as God's manifest form (29), doctors might try to live up to patients' expectations by enacting the role of the kind and attentive healer they personify in their profession. By carefully nurturing the impressions they create about their skills and practice, doctors can better play their role of provider of relief from suffering, knowing that their every word, act and look is medicinal. This would also go a long way in addressing some of the inherent inequities of the medical service delivery culture.

\section{References}

1. van Ryn M, Fu SS. Paved with good intentions: do public health and human service providers contribute to racial/ethnic disparities in health? Am J Public Health. 2003 Feb; 93 (2): 248-255.

2. Kwintner $M$. When absence speaks louder than words: an object relational perspective on no-show appointments. Clin Soc Work J. 2011 
Jan 24:1-9. doi:10.1007/s10615-011-0313-x

3. Commission on Social Determinants of Health (2008).Closing the gap in a generation: health equity through action on the social determinants of health- Final report of the Commission on Social Determinants of Health. Geneva:WHO;2008.

4. Di Blasi Z, Harkness E, Ernst E, Georgiou A, Kleijnen J. Influence of context effects on health outcomes: a systematic review. Lancet. 2001 Mar 10; 357(9258):757-62.

5. Haug MR. The effects of physician/elder patient characteristics on health communication. Health Commun. 1996 Jul; 8(3): 249-62.

6. Willems S, De Maesschalck S, Deveugele M, Derese A, De Maeseneer J. Socio-economicstatus of the patient and doctor-patient communication does it make a difference? Patient Educ Couns. 2005 Feb; 56(2):139-46.

7. Courtright $P$, Lewallen $S$.Improving gender equity in eye care:advocating for the needs of women. Community Eye Health J. 2007; 20(64):68-9.

8. Baum F. Cracking the nut of health equity: top down and bottom up pressure for action on the social determinants of health. Promot Educ. 2007;14(2):90-5.

9. Deane J.Communication, cooperation, leadership-priorities for the new WHO Director-General. Lancet. 2003 Jan 4;361(9351):7.

10. Stewart M, Brown JB, Donner A, McWhinney IR, Oates J, Weston WW, Jordan J. The impact of patient-centred care on outcomes. J Fam Pract. 2000 Sep; 49(9):796-804.

11. Epstein A, Ayanian J. Racial disparities in medical care. New Engl J Med. 2001 May 10; 344(19):1471-3.

12. Muurinen J, Le Grand J.The economic analysis of inequalities in health. Soc Sci Med. 1985;20(10):1029-35.

13. Waitzkin H. Doctor-patient communication: Clinical implications of social scientific research. JAMA. 1984 Nov 2;252(17):2441-6.

14. Clark NM, McLeroy KR. Creating capacity through health education: what we know and what we don't. Health Educ Q. 1995 Aug;22(3):27389.

15. Perez-Stable EJ, Napoles-Springer A, Miramontes JM. The effects of ethnicity and language on medical outcomes of patients with hypertension or diabetes. Med Care.1997 Dec;35(12):1212-9.

16. Katz MG, Jacobson TA, Veledar E, Kripalani S. Patient literacy and question-asking behavior during the medical encounter: a mixedmethods analysis.J Gen Intern Med. 2007Jun;22(6):782-6.

17. Konski A, Berkey BA, Ang KK, Fu KK. Effect of Education Level on Outcome of Patients Treated on Radiation Therapy Oncology Group Protocol 9003. Cancer. 2003 Oct 1;98(7):1497-503.
18. Vieder JN, Krafchick MA, Kovach AC, Galluzzi KE. Physician-patient interaction: what do elders want? J Am Osteopath Assoc. 2002 Feb 1;102(2):73-8.

19. Office of the Chief Medical Health Officer, Vancouver Island Health Authority (2006). Understanding the Social Determinants of Health. A Discussion Paper. Vancouver Island Health Authority.

20. Mead N, Bower P, Hann M. The impact of general practitioners' patientcentredness on patients' post-consultation satisfaction and enablement. Soc Sci Med. 2002 July; 55(2):283-99.

21. Commission on the Social Determinants of Health.Challenging inequity through health systems. Final report - Knowledge Network on Health Systems. Geneva:WHO;2007.

22. Betancourt JR. Improving quality and achieving equity: the role of cultural competence in reducing racial and ethnic disparities in health care. The Commonwealth Fund. 2006

23. Lawson PJ, Flocke SA.Teachable moments for health behavior change: $A$ concept analysis. Patient Educ Couns. 2009 Jul;76(1):25-30.

24. Schoenthaler A, Chaplin WF, Allegrante JP, Fernandez S, Diaz-Gloster $M$, Tobin JN, Ogedegbe G. Provider communication effects medication adherence in hypertensive African Americans. Patient Educ Couns. 2009 May;75(2):185-91.

25. Buetow SJ, Annemarie, Hoare K. Shrinking social space in the doctormodern patient relationship: A review of forces for, and implications of, homologisation. Patient Educ Couns. 2009 Jan;74(1):97-103. Epub 2008 Sep 11.

26. Mocherla S, Raman U, Holden BA. Clinician-patient communication in a glaucoma clinic in India. Qual Health Res 2011 Mar;21(3):429-40. Epub 2010 Nov 1.

27. Beach MC, Price EG, Gary TL, Robinson KA, Gozu A, Palacio A, Smarth C, Jenckes MW, Feuerstein C, Bass EB, Powe NR, Cooper LA. Cultural competence: a systematic review of health care provider educational interventions. Med Care. 2005Apr; 43(4):356-73.

28. Marmot M, Allen J, Bell R, Goldblatt P. Building of the global movement for health equity: from Santiago to Rio and beyond. Lancet[Internet]. 2011 October 19[cited 2012 Mar 6]. doi:10.1016/S0140-6736(11)615067 Available from: http://www.thelancet.com/journals/lancet/article/ PIIS0140-6736\%2811\%2961506-7/abstract

29. Broddason T. The sacred side of professional journalism. Eur $J$ Communication. 1994; 9(3):227-48.

\title{
Awareness of medical ethics among undergraduates in a West Bengal medical college
}

\author{
BISWAJIT CHATTERJEE', JHUMA SARKAR ${ }^{2}$
}

${ }^{1}$ MBBS student, ${ }^{2}$ Assistant Professor, Department of Community Medicine, Midnapore Medical College, Paschim Medinipur, West Bengal 721101 INDIA Author for correspondence: Biswajit Chatterjee e-mail: biswajit.bapin@gmail.com

\begin{abstract}
This descriptive, cross-sectional study was conducted to assess the knowledge of and attitudes towards medical ethics among undergraduate medical students. It also looked at whether there was any improvement with additional years of medical education. 340 medical students of a medical college in West Bengal were given a semi-structured questionnaire that included questions regarding their awareness of ethics, their attitudes towards various issues in clinical ethics, and their knowledge of the code of medical ethics of the West Bengal Medical Council. The responses of 322 students were analysed by simple descriptive statistics.
\end{abstract}

The students generally agreed that awareness of ethics was important. Lectures (54.7\%) and books (47.8\%) were their predominant sources of knowledge. Only $10.9 \%$ were aware of the existence of an institutional ethics committee and $42.8 \%$ did not know its exact role. Their answers showed that the majority of students expressed mixed responses - both desirable and undesirable - in relation to questions exploring different aspects of basic ethical reasoning in their professional life. The most desirable response for each statement was decided by experts of forensic medicine and also from a literature study. Only half the respondents (50.9\%) had a good score (61-70 out of a total possible 90) and $37.2 \%$ had a fair score (51-60). There was no 